\title{
Motivações semântico-cognitivas e interacionais na codificação do modificador nominal
}

\author{
Semantic-cognitive and interactional motivations in the codification \\ of the noun modifier
}

\author{
Lígia Maria da Silva* \\ ligiamdsilva@gmail.com \\ Rede Estadual de Ensino do Rio Grande do Norte
}

\begin{abstract}
RESUMO: Este trabalho investiga a relação entre Nome $(\mathrm{N})$ e modificador (Mod) no interior do Sintagma Nominal (SN). Objetiva analisar as formas de codificação do modificador nominal com base em aspectos semânticos, cognitivos e comunicativos. O aporte teórico é a Linguística Funcional Centrada no Uso (FURTADO DA CUNHA; BISPO; SILVA, 2013), segundo a qual as formas da língua possuem estreita ligação com as funções a que elas servem em contexto efetivo de interação verbal. $O$ corpus é formado por textos publicados nas edições do primeiro semestre de 2011 da Revista Veja, representativos de dois gêneros textuais: Editorial e Coluna Social. Os resultados revelam que o tipo de codificação do modificador nominal mais integrado ao nome é o adjetivo, que representa a forma menos complexa, não marcada e, portanto, mais recorrente, em comparação com a locução adjetiva e com a oração relativa.
\end{abstract}

PALAVRAS-CHAVE: Modificador nominal. Relação forma-função. Motivações. Linguística Funcional.

ABSTRACT: This paper focuses on the relationship between Noun $(N)$ and its modifier (Mod) in Noun Phrases (NP). It aims to analyze semantic, cognitive and communicative aspects involved in the levels of $\mathrm{N}$-Mod integration and the motivations for choosing the form of encoding the noun modifier. The theoretical framework is based on Linguística Funcional Centrada no Uso (FURTADO DA CUNHA; BISPO; SILVA, 2013), according to which the linguistic structure is very close to its functions in verbal interaction. The corpus consists of texts published in Veja Magazine issues of the first half of 2011 that represent two text genres: Editorial and Social Column. The results reveal that the more integrated type of noun Mod is the adjective, which represents the least complex and unmarked form; it is, therefore, more recurrent if compared the adjectival phrases and relative clauses.

KEYWORDS: Noun modifier. Form-function relationship. Motivations. Linguística Funcional Centrada no Uso.

\footnotetext{
Mestra pelo Programa de Pós-Graduação em Estudos da Linguagem, professora de Língua Portuguesa da Rede Estadual de Ensino do Rio Grande do Norte.
} 


\section{Introdução}

Os estudos baseados na língua em uso evidenciam, por meio das diversas pesquisas sobre os mais variados fenômenos linguísticos, que as escolhas de determinadas formas linguísticas pelo falante advêm de motivações semânticas, cognitivas e comunicativas implicadas nos diversos contextos de interação.

Esses trabalhos reconhecem o relevante papel que fatores de natureza comunicativa/interacional e cognitiva desempenham na configuração estrutural de que se revestem variadas construções linguísticas. Isso equivale a dizer, em outras palavras, que há, de algum modo, uma motivação entre forma e função. Assim, a codificação linguística de determinadas estruturas tem a ver com as funções que elas desempenham e se relaciona diretamente aos propósitos que se quer alcançar na interação discursiva.

A partir do exposto, justifica-se a relevância do estudo da língua em uso, conforme é defendido pelos funcionalistas. De acordo com a perspectiva funcional da língua, o fenômeno linguístico deve ser tomado como produto e processo da interação humana, da atividade sociocultural. Sob essa ótica, os sentidos veiculados pelas estruturas da língua têm relação motivada, o que significa que estas são moldadas em termos daqueles.

Nesse contexto, este trabalho objetiva investigar a relação entre nome $(N)$ e modificador (Mod), seja adjetivo, locução adjetiva ou oração relativa, no interior do sintagma nominal, com o intuito de identificar possíveis motivações para os níveis de integração sintático-semântica entre $\mathrm{N}$ e Mod. Focaliza, portanto, o estudo da língua em uso, conforme uma abordagem centrada no uso (MARTELOTTA, 2011), e trata, especialmente, de algumas categorias centrais do funcionalismo, que são os princípios de iconicidade e de marcação, além da perspectivação.

Contemplam-se aqui achados sobre o fenômeno investigado, os quais constituem respostas parciais e preliminares para algumas das indagações que sustentam esta pesquisa, quais sejam: de que maneira se dá a relação forma-função na integração N-Mod? Que motivações semânticas, cognitivas e interacionais estão implicadas nessa integração? Que fatores motivam a escolha do tipo de Mod empregado em dado SN? 


\section{Aspectos teóricos}

A teoria que embasa esta investigação é a Linguística Funcional Centrada no Uso (LFCU). Cunhado no âmbito do Grupo de Estudos Discurso \& Gramática (D\&G), o termo LFCU representa desdobramento do que Matelotta (2011) denominou Linguística Centrada no Uso, que corresponde, em termos teóricos e metodológicos, à Linguística Cognitivo-Funcional (TOMASELLO, 1998) e a Usage-based Linguistics, nos termos de Bybee (2010). Essa abordagem teórica reúne contribuições dos estudos da Linguística Funcional representada por autores como Heine (1994), Givón (1990, 2012 [1979]), Furtado da Cunha et al (2003), Bybee (2010), Martelotta (2011), da Linguística Cognitiva, tal como sustentada por Lakoff e Johnson (1980, 1999), Langacker (1987), e da Psicolinguística, como Taylor (1992, 1998) e Tomasello (1998).

Segundo essa perspectiva teórica, há uma estreita relação entre a estrutura linguística e os usos que dela se fazem na interação social, de modo que a configuração morfossintática dos enunciados é fortemente motivada por fatores decorrentes da situação comunicativa. Assim, a análise linguística, nessa perspectiva, considera fatores relacionados aos interlocutores, a seus propósitos comunicativos e ao contexto discursivo ${ }^{1}$ em que os fenômenos sob estudo ocorrem.

Nessa concepção, evidencia-se a importância da relação entre o estudo do discurso e da gramática, partindo do princípio de que a estrutura gramatical é motivada por fatores de natureza comunicativa. Dessa forma, podemos dizer que há relação de motivação mútua entre gramática e discurso.

Um dos princípios básicos da LFCU é o fato de que a estrutura da língua emerge à medida que esta é usada. Com base nessa perspectiva, deve-se, então, descrever e explicar os fatos linguísticos com base nas funções (semânticocognitivas e discursivo-pragmáticas) que desempenham nos diversos contextos de uso da língua, integrando sincronia e diacronia, numa abordagem pancrônica (BYBEE, 2010).

\footnotetext{
${ }^{1}$ Entende-se aqui contexto discursivo como a situação concreta de uso da língua, o que inclui os participantes da interação verbal, os propósitos comunicativos implicados, características do gênero textual em uso, entre outros.
} 
Diante disso, o estudo de fenômenos linguísticos que se dê com base em contextos reais de comunicação é de extrema importância, tanto de fala quanto de escrita. Entende-se, assim, que os aspectos comunicativos, sociais e culturais, além de cognitivos, exercem influência significativa na estrutura da língua.

Entre os princípios, processos e categorias de análise da LFCU, faremos uso neste trabalho dos princípios de iconicidade e de marcação, além da perspectivação para dar conta dos níveis de integração $\mathrm{N}$-Mod e das formas de codificação do modificador nominal.

A iconicidade refere-se à correlação natural entre a expressão linguística e seu conteúdo, de modo que se entende, com base no funcionalismo, que a estrutura da língua reflete, de algum modo, a estrutura da experiência (FURTADO DA CUNHA et al., 2003).

Conforme Givón (1990), a iconicidade compreende três subprincípios, a saber: quantidade, proximidade e ordenação linear. Eles estão relacionados à quantidade de informação, ao grau de integração entre os constituintes da expressão e do conteúdo e à ordenação sequencial dos segmentos (FURTADO DA CUNHA, 2008). Vejamos cada um dos subprincípios a seguir.

Subprincípio da quantidade: indica que quanto maior for a quantidade de informação, maior será a forma para codificá-la, de modo que a estrutura da construção gramatical indica a estrutura do conceito que ela expressa (FURTADO DA CUNHA et al., 2003). Em outras palavras, podemos dizer que a complexidade de pensamento tende a refletir-se na complexidade de expressão (SLOBIN, 1980). Assim, aquilo que é mais simples e esperado se expressa com o mecanismo morfológico e gramatical menos complexo.

Subprincípio da proximidade: considera que os conteúdos mais próximos funcional, conceptual e cognitivamente estarão também mais integrados no nível da codificação, ou seja, o que está mais próximo cognitivamente também estará mais próximo morfossintaticamente, como, por exemplo, os afixos, pois possuem uma estreita relação com os radicais a que se vinculam. De modo oposto, conceitos menos integrados no plano cognitivo se apresentarão com menor integração no plano da codificação morfossintática, como acontece com as desinências de gênero e/ou de número em relação ao radical, se comparadas com os afixos.

Subprincípio da ordenação linear: caracteriza-se por dois aspectos básicos, que dizem respeito à ordem da informação, pois considera que a mais tópica tende a 
aparecer primeiro - como, por exemplo, o fato de o sujeito normalmente ocupar a primeira posição no enunciado -, e à ordem das orações no discurso, que corresponde à sequência temporal dos acontecimentos dos eventos apresentados (FURTADO DA CUNHA; BISPO; SILVA, 2013).

Já o princípio de marcação diz respeito à presença ou ausência de uma propriedade nos membros de um par contrastante numa dada categoria linguística (FURTADO DA CUNHA, 2001). Existem três critérios principais que podem ser usados para distinguir uma categoria marcada de uma não marcada, num contraste binário (GIVÓN, 1990). São eles:

a) complexidade estrutural: a categoria marcada tende a ser mais complexa que a estrutura não marcada correspondente.

b) distribuição de frequência: a estrutura marcada normalmente é menos frequente que a estrutura não marcada.

c) complexidade cognitiva: a estrutura marcada tende a ser mais complexa cognitivamente que a correspondente não marcada.

Esses critérios de marcação normalmente coincidem nas línguas, em geral, havendo, pois, uma correlação entre marcação estrutural, marcação cognitiva e baixa frequência de ocorrência, o que é o reflexo mais geral da iconicidade na gramática (FURTADO DA CUNHA et al., 2003).

Quanto à perspectivação, ela diz respeito ao direcionamento da atenção sobre um evento referencial; isto é, tem a ver com a focalização de aspectos específicos de uma cena (TOMASELLO, 1998). Nesse sentido, ao relatar um determinado evento ou descrever uma dada situação, o usuário da língua escolhe um elemento particular como o ponto de vista a partir do qual esse evento/situação é comunicado/a.

\section{Aspectos metodológicos}


Metodologicamente, o tipo de pesquisa que realizamos é eminentemente qualitativo, pois busca elucidar motivações semânticas, interacionais e cognitivas na codificação do modificador no interior do sintagma nominal. Além disso, ele tem suporte quantitativo, no que se refere ao aspecto mensurável dos dados e à caracterização do objeto de estudo e sua frequência de uso.

A fonte dos dados para esta investigação são textos das seções "Carta ao leitor" e "Gente" da Revista Veja, publicados nas edições do $1^{\circ}$ semestre de $2011^{2}$ totalizando 26 edições. Tais seções correspondem o Editorial e a Coluna Social, respectivamente, desse periódico semanal.

A opção por esses dois gêneros textuais se deve ao fato de representarem duas situações distintas de uso da língua: uma envolvendo mais formalidade, outra com uso menos formal. Além disso, o propósito comunicativo com que esses dois gêneros textuais emergem também se distinguem. Em termos de conteúdo temático, no Editorial, com frequência, estão questões políticas, econômicas e culturais. Como é característico desse gênero textual, o Editorial expressa a opinião da equipe de redação acerca, principalmente, de um dos temas que tem mais destaque na edição. Já a Coluna Social reúne informações - que nem sempre são notícias - e imagens a respeito de personalidades famosas na sociedade, não somente no âmbito nacional, mas também internacional.

Desse modo, os exemplares textuais considerados para levantamento dos dados permitem correlacionar as formas de codificação do modificador nominal e sua integração com o núcleo do $\mathrm{SN}$ a situações efetivas de uso da língua e a questões interacionais, semânticas e cognitivas.

A partir da seleção do material de pesquisa, procedeu-se ao levantamento de dados para análise. Foram identificadas e tabuladas todas as ocorrências de adjetivo adjunto, locução adjetiva e oração adjetiva desenvolvida ou reduzida.

\section{Análise dos dados}

No que se refere ao quantitativo dos dados, foram identificadas 1212 ocorrências de modificador nominal na Coluna Social, sendo 785 adjetivos, 356

\footnotetext{
${ }^{2}$ Os resultados discutidos neste artigo são fruto de uma pesquisa desenvolvida, no âmbito da Iniciação Científica, entre 2011 e 2012, daí a escolha pelas edições referidas.
} 
locuções, e 71 orações relativas. Quanto ao Editorial, identificaram-se 1413 ocorrências, das quais 824 representavam adjetivos, 371 eram locuções, e 218 constituíam orações relativas. Pode-se notar que o adjetivo é o tipo de codificação do Mod mais recorrente, e representa uma quantidade significativa de ocorrências totais constatadas tanto na Coluna Social quanto no Editorial, alcançando, em ambos, percentual superior a 50\%, como se observa no gráfico a seguir:

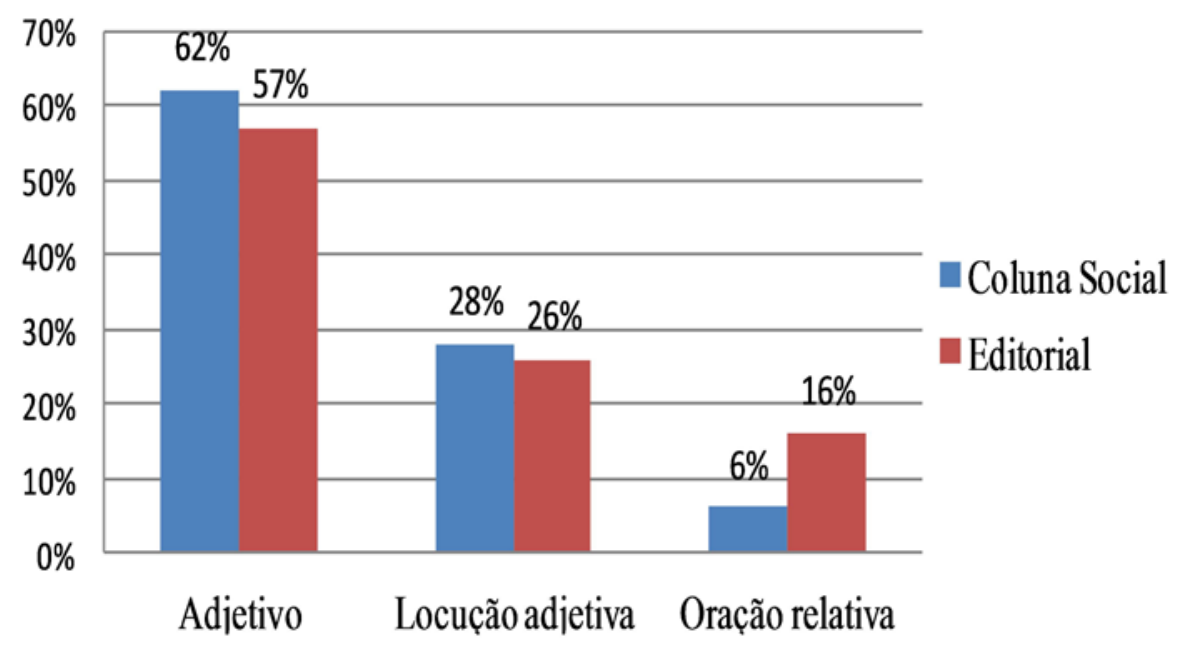

Gráfico 1 - Distribuição dos Mod no corpus, por tipo de codificação

Outro aspecto observado no corpus analisado diz respeito à ordenação dos elementos que codificam o Mod, quando pospostos ao núcleo do SN. Com base nos dados, constatou-se que a ordem mais recorrente, quando são usadas pelo menos duas formas de codificação, é a seguinte: adjetivo - locução adjetiva - oração relativa. Isso mostra que o adjetivo representa a forma mais integrada de modificador nominal, ao passo que a oração relativa exibe menor vinculação. As amostras a seguir exemplificam tanto as diferentes formas de codificação do Mod encontradas no corpus quanto a ordenação desses elementos.

(1) "[...] de elevar em 0,5 ponto percentual a taxa básica de juros, a Selic, que determina o custo mínimo do dinheiro no mercado interbancário [...]" (Editorial, 26/01/2011)

(2) "Ou vontade irresistível de ficar com o rosto afilado e triangular que está na moda entre os famosos." (Coluna Social, 18/05/2011)

Em (1), destaca-se a ocorrência dos três modos de codificação estrutural do Mod relacionados a um mesmo nome (taxa), dispostos na sequência adjetivo - 
locução adjetiva - oração relativa. Em (2), verifica-se que, mesmo quando há ocorrência de apenas duas formas de codificação, a ordem de precedência é mantida: adjetivo e locução, adjetivo e oração, locução e oração, etc. Considerando, ainda, todo o corpus, constatou-se que a quantidade de ocorrências com a ordem não prototípica é insignificante, pois praticamente não ocorre.

Quanto à posição do Mod em relação ao nome, observa-se que o adjetivo, além de ser o mais recorrente e o mais integrado, é também o mais "flexível", já que pode vir tanto antes quanto depois do elemento a que se refere, enquanto as locuções adjetivas e as orações relativas não precedem o termo modificado.

Com base na análise qualitativa dos resultados da pesquisa, mais especificamente relacionada às diferentes formas de codificação do modificador nominal e à ordenação dessas formas no SN que integram, pôde-se observar que há motivações, de naturezas distintas, implicadas na forma escolhida pelo falante/escritor. Dito isso, o que segue constitui discussão dos resultados obtidos à luz dos princípios funcionalistas de iconicidade e de marcação.

Conforme exposto em seção anterior, o princípio de iconicidade refere-se à correlação natural entre a expressão linguística e seu conteúdo, de modo que se entende, com base no funcionalismo, que a estrutura da língua reflete, de algum modo, a estrutura da experiência (BISPO, 2009). Assim, trazendo a questão para o foco desta pesquisa, no que se refere à relação forma-função, a maior proximidade entre as formas de codificação do Mod e o nome por ele escopado pode refletir a maior integração, no plano do conteúdo, que há entre esses elementos.

Como mostram os dados da pesquisa, dentre as três formas de codificação do modificador nominal, o adjetivo é o elemento que se posiciona mais contiguamente ao nome a que se refere, sendo, portanto, mais integrado a este em comparação com a locução adjetiva e a oração relativa.

O excerto (3) ilustra esse nível de integração sintática, que corresponde também à integração no plano do conteúdo: o adjetivo "feminina" aparece como a forma mais integrada sintaticamente (está mais próximo do nome modificado parte); no plano do conteúdo, esse adjetivo responde pela primeira delimitação/ especificação/ recorte do núcleo do $\mathrm{SN}$, estando, pois, conceptualmente mais integrado que as demais formas de Mod empregadas (locução adjetiva e oração relativa). 
(3) "[...] todo mundo dá uma olhadinha, em especial a parte feminina da população que adora analisar as roupas e concluir que a mais bonita é a mais magra." (Coluna Social, 09/03/2011)

A ordenação mais recorrente das formas de codificação do Mod nominal verificada no corpus desta pesquisa (adjetivo - locução adjetiva - oração relativa) pode ser também analisada à luz do princípio de marcação.

Considerando-se os critérios para distinguir uma categoria marcada de uma não marcada e propondo-se um contínuo de marcação, pode-se dizer que o adjetivo é a forma não marcada em oposição às demais. Isso porque ele é menos complexo estrutural (é menor) e cognitivamente (demanda menor tempo de elaboração e processamento, pelo menos) em relação à locução adjetiva (estrutura marcada) e à oração relativa (mais marcada).

Levando-se em conta os resultados quantitativos a que se chegou quanto à forma mais frequente de Mod e quanto à ordem mais recorrente de disposição dessas formas, pode-se constatar que essa ordenação exibe uma escala que vai da estrutura não marcada (o adjetivo) para a mais marcada (a oração relativa). Correlacionando esses achados com o nível de integração do Mod ao núcleo do SN, percebe-se que a estrutura não marcada é a mais integrada; por oposição, a estrutura mais marcada seria menos integrada.

Quanto à frequência de uso, os dados revelam ser o adjetivo a forma mais recorrente de codificação do Mod nominal, e isso se coaduna perfeitamente com o princípio de marcação, segundo o qual as formas menos marcadas estrutural e cognitivamente são as mais frequentes. Isso implica que, em contrapartida, as estruturas mais complexas (locução adjetiva e oração relativa, no caso) são menos frequentes, conforme atestam os resultados extraídos do corpus analisado. De todas as formas, a oração relativa mostra-se como a mais complexa, já que é um elemento mais elaborado, mais longo e que exige mais esforço de codificação e processamento, comparada à forma não marcada ou à marcada (adjetivo e locução adjetiva, respectivamente).

A opção por uma ou outra forma de codificação do Mod nominal também pode relacionar-se a fatores interacionais/ comunicativos. Assim, o emprego de uma oração relativa ou de um adjetivo semirrelativo correspondente, por exemplo, tem a ver com o modo como o enunciador concebe um dado evento ou com a maneira que 
pretende comunicá-lo: como produto ou processo. É o que se dá, por exemplo, em (4).

(4) "Ao lado de Adriana Lima, 29, e Alessandra Ambrósio, 29, há mais tempo na casa, por isso, com direito adquirido de ficar mais cobertas e até mais "cheinhas" (Coluna Social, 06/04/2011)

Note-se que o uso da forma adquirido em vez de uma oração relativa correspondente (que [se] adquiriu) implica, do ponto de vista da perspectivação do evento, a ênfase no resultado (produto), que, no caso, é a obtenção do direito, ou melhor, a posse dele, e não o processo implicado nessa obtenção. Além disso, permeia essa escolha o princípio da economia, dado o fato de que a forma semirrelativa envolve redução estrutural em comparação com a relativa.

Assim, pode-se perceber que a escolha de uma oração relativa (desenvolvida ou reduzida) ou de um adjetivo semirrelativo é motivada por fatores semânticocognitivos e discursivo-pragmáticos. Isso implica que o falante/escritor opta pela forma que melhor representa a perspectiva sob a qual pretende comunicar o evento, considerando também o menor custo cognitivo implicado nessa escolha.

Outro aspecto que merece consideração diz respeito à natureza dos gêneros textuais que compõem o corpus desta análise. No Editorial (Carta ao leitor), encontram-se muitas informações novas, o que implica a utilização de estruturas com mais material linguístico para explicar, restringir, caracterizar, de modo mais preciso, determinado elemento, como é o caso da oração relativa. Já a Coluna Social (seção Gente) representa um texto mais informal, que envolve assuntos banais, fofocas (daí mais conhecidos), que evocam informações mais contextuais, favorecendo o uso de estruturas menos complexas, como é o caso da locução adjetiva e, principalmente, do adjetivo simples. Essa distinção pode explicar a diferença na frequência da oração relativa (forma mais complexa de Mod nominal) nos dois gêneros textuais: Editorial (com 16\%) e Coluna Social (6\%).

Portanto, a escolha do tipo de modificador advém, como já dito anteriormente, de motivações tanto semântico-cognitivas quanto interacionais, de modo a atender às necessidades e propósitos dos interlocutores engajados em situações reais de interação verbal. 


\section{Considerações finais}

A partir dos resultados obtidos nesta pesquisa, foi possível fazer uma breve análise a respeito das motivações semântico-cognitivas e interacionais implicadas na escolha da codificação do Mod nominal.

Os resultados coadunam-se com alguns pressupostos funcionalistas abordados neste trabalho, principalmente no que se refere aos níveis de integração entre o nome e seu modificador, relacionados aos princípios de iconicidade e de marcação e à perspectivação.

De modo específico, verificou-se que o tipo de codificação do Mod mais integrado ao nome é o adjetivo, que representa a forma menos complexa, não marcada e, portanto, mais recorrente, em comparação com a locução adjetiva e a oração relativa. Também se observou que, em determinados contextos, faz-se necessário o uso de formas linguísticas mais complexas para melhor descrever, modificar e explicar um dado termo, conforme as pretensões do falante/escritor.

Em suma, as considerações constantes deste artigo abordam um pequeno recorte tanto em termos de material analisado quanto de teoria discutida. Destacase, portanto, a continuidade de pesquisas pautadas nos pressupostos da língua em uso, para que se possa chegar a outros resultados, quer em relação ao fenômeno aqui focalizado, quer em relação a outros fenômenos linguísticos, associados a outros contextos comunicativos que implicarão, certamente, outras motivações.

\section{Referências}

BISPO, Edvaldo Balduino. Estratégias de relativização no português brasileiro e implicações para o ensino: o caso das cortadoras. Tese (Doutorado em Estudos da Linguagem), Universidade Federal do Rio Grande do Norte, Natal, 2009.

BYBEE, Joan. Language, usage, and cognition. Cambridge, UK: CUP, 2010.

FOX, Barbara A.; THOMPSON, Sandra A. Relative clauses in English conversation: relativizers, frequency, and the notion of construction. Studies in Language 31:2, 2007, p. 293-326.

FURTADO DA CUNHA, Maria Angélica. Funcionalismo. In: MARTELOTTA, Mário Eduardo. (org.). Manual de linguística. São Paulo: Contexto, 2008, p. 235-242. 
. Análise funcionalista de procedimentos discursivos. In: PASSEGGI, L.; OLIVEIRA, M. do S. (Orgs.). Linguística e educação: gramática, discurso e ensino. São Paulo: Terceira Margem, 2001, p. 55-76.

; BISPO, Edvaldo Balduino; SILVA, José Romerito. Linguística Funcional Centrada no Uso: conceitos básicos e categorias analíticas. In: CEZARIO, Maria Maura; FURTADO DA CUNHA, Maria Angélica (Orgs.). Linguística Centrada no Uso: uma homenagem a Mario Martelotta. Rio de Janeiro/ Cataguases-MG: FAPERJ/Mauad, 2013, p. 13-36.

FURTADO DA CUNHA, Maria Angélica et al. Pressupostos teóricos fundamentais. In: FURTADO DA CUNHA, Maria Angélica; OLIVEIRA, Mariangela Rios de; MARTELOTTA, Mário Eduardo (Orgs.). Linguística funcional: teoria e prática. Rio de Janeiro: DP\&A, 2003, p. 29-55.

GIVÓN, Talmy. A compreensão da gramática. Tradução Maria Angélica Furtado da Cunha et al. São Paulo: Cortez, 2012.

Syntax: a functional-typological introduction. v. II. Philadelphia: John Benjamins, 1990.

HEINE, Bernd. Grammaticalization as an exploratory parameter. In: PAGLIUCA, W. (Ed.). Perspectives on grammaticalization. (Current issues in linguistic theory). v. 109. Amsterdam/ Philadelphia: John Benjamins, 1994, p. 255-287.

LAKOFF, George; JOHNSON, Mark. Philosophy in the flesh. New York: Basic Books, 1999.

Metaphors we live by. Chicago: University of Chicago Press, 1980.

LANGACKER, Ronald W. Foundations of cognitive grammar. Theoretical prerequisites. Stanford: SUP, 1987.

MARCUSCHI, Luiz Antônio. Gêneros textuais: definição e funcionalidade. In: DIONÍSIO, Ângela Paiva; MACHADO, Ana Raquel; BEZEERRA, Maria Auxiliadora. Gêneros textuais e ensino. 4. ed. Rio de Janeiro: Lucerna, 2005, p. 19-36.

MARTELOTTA, Mário Eduardo. Mudança linguística: uma abordagem baseada no uso. São Paulo: Cortez, 2011.

SILVA, Ademar da. A ordem dos adjetivos em grupos nominais: uma questão sintático-semântica e discursiva. Disponível em: http://www.unisinos.br/publicacoes_cientificas/images/ stories/pdfs_calidoscopio/vol6n3/134a141_art02_silva.pdf. Acesso em 02 abr. 2011.

SLOBIN, Dan Isaac. Psicolingüística. São Paulo: Nacional/EDUSP, 1980.

TAYLOR, John R. Syntactic construction as prototype categories. In: TOMASELLO, Michael (Ed.). The new psychology of language. New Jersey: Lawrence Erlbaum, 1998. 
$\mathbb{O}_{\text {disge }} \mathcal{A}$

Linguistic categorization: prototypes in linguistic theory. Great Britain: Laredan Paper backs, 1992.

TOMASELLO, Michael (ed.). The new psychology of language. New Jersey: Lawrence Erlbaum, 1998.

TUCKER, Gordon H. The lexicogrammar of adjectives: a systemic functional approach to lexis. London/New York: Cassel, 1998.

Recebido em 15/07/2016

Aceito em 23/08/2016 